\title{
Expressões impessoais no discurso acadêmico brasileiro
}

\author{
Impersonal expressions in Brazilian academic speech
}

\author{
Marcia dos Santos Machado Vieira ${ }^{1}$
}

Professora Doutora do Programa de Pós-Graduação em Letras Vernáculas da UFRJ, coordena o Projeto de Pesquisa PREDICAR - Formacão e expressão de predicados complexos: estabilidade, variação e E-mail: marciamv@uffij
RESUMO: Este artigo enfoca a comparabilidade de microconstruções com ter-se e haver relacionadas ao domínio funcional da impessoalização discursivo-pragmática, da construção gramatical de impessoalização. Esse estudo descreve, com base no Sociofuncionalismo, o aumento da frequência da recorrência a instâncias da microconstrução com ter-se num intervalo de tempo e os condicionamentos da variação (estável) de usos desse padrão gramatical com os da microconstrução com o verbo haver: a área acadêmica e a semântica de SN, por exemplo. A mudança que se nota na microconstrução ter-se $S N$ decorre da cristalização sintática de seus componentes e da associação de sua extensão de sentido indefinido com uma extensão de sentido impessoal (existencial ou apresentacional), o que propicia sua equivalência funcional com construções com haver e sua atuação como estratégia discursivo-pragmática que possibilita tornar opaca a presença do enunciador. Os resultados advêm de análise estatística e qualitativa de usos detectados em textos acadêmicos de áreas distintas do conhecimento. Tencionase, em última instância, contribuir também para a discussão teórica sobre o lugar da variação em estudos sob a ótica da Gramática das Construções, que, até então, se tem voltado para o fenômeno da mudança linguística.

PALAVRAS-CHAVE: Sociofuncionalismo; Impessoalização; Microconstruções verbais.

ABSTRACT: This paper deals with the comparability of microconstructions with ter-se and haver (in english, there to be) related to the functional area of discursive and pragmatic impersonality, to impersonality grammatical construction. This study describes, according to Sociofunctionalism, the increase of frequency of the recurrence to instances of the microconstruction with ter-se in an interval of time and the restrictions of the (stable) variation of uses of such grammatical form with the ones of the microconstruction with verb haver: the academic area and the semantic of the SN, for example. The change which is observed at the microconstruction which contains ter-se is explained by its sytactic fixation and the association of its indefinite meaning use with an impersonal (existential or presentational) meaning, phenomenon which gives rise to its functional equivalence with haver and its use as a discursive strategy to dim the speaker presence. The results are based on the statistical and qualitative analysis of the uses detected in the academic texts from different areas of knowledge. We also aim as far as possible, to contribute to debates about the locus of variation at studies developed according to Construction Grammar, which has been dedicated to linguistic change phenomenon.

KEYwoRDS: Sociofunctionalism; Impersonalisation; Verbal microconstructions. 


\section{Introdução}

4 ste ste artigo centra-se no estudo da relação de comparabilidade funcional entre as seguintes microconstruções ${ }^{1}$ formadas pelas formas ter-se e haver na terceira pessoa:

(i) ter ao qual se liga o clítico $s e+\mathrm{SN}$

Ex.1: "No modelo teórico sugerido por Leon-Ledesma, apresentado na seção anterior, tem-se a hipótese de que o valor agregado das exportações depende da relação preços internos/preços externos e da renda mundial, juntamente com os fatores de competitividade non-price." [RC, 2004]

Ex. 2: "Agrupando as variáveis da QS do atributo conforto de acordo com as listas de variáveis apresentadas no item 3.4 , tem-se a seguinte relação: Desenho das vias \{quantidade de travessias\}, Linearidade dos Caminhos e Grau de Ocupação das calçadas." [DM², 2014]

(ii) haver impessoal $+\mathrm{SN}$

Ex. 3: “Também foi realizada uma análise do texto, baseada em suas inúmeras ambiguidades, com a qual se constatou, desde a possibilidade de uma classificação em dois gêneros distintos, até a duplicidade de intenções. Se por um lado há o propósito de parodiar os antigos tratados, por outro existe a denúncia da moral dupla de seu tempo. Pela análise do texto dentro do seu contexto, não apenas os fatos literários, mas também os linguísticos adquirem maior transparência." [DM, 2003]

Ex. 4: "Para a qualidade no setor de serviços a terceira abordagem é a mais adotada, pois, apesar de não haver na literatura uma convergência de

\footnotetext{
1 Microconstrução é um construto teórico, na Gramática Construcional, que designa um subtipo de padrão construcional gramatical (pareamento forma-função) de uma rede de construções, está disponível na memória e corresponde ao nível de abstração mais próximo ao da instanciação em texto/discurso. 2 Utilizam-se, na indicação das fontes dos dados do domínio acadêmico, estas informações: (i) gênero textual, entendido aqui como estrutura textual relativamente estável (DM - Dissertação de Mestrado; RC - resumo submetido a evento científico; AC - artigo científico em periódico; AG - avaliação/prova
} (de divulgação) do texto.
(diraduação; ERV - entrevista no Programa Roda Viva/TV Cultura); (ii) ano opiniões, um ponto comum entre todas as definições da Qualidade de Serviço é a percepção do usuário." [DM, 2014]

Acredita-se que tais microconstruções se encontram em variação, uma vez que se alinham funcionalmente a serviço do fenômeno de impessoalização em textos orais e escritos produzidos no Brasil. E essa variação tem sido percebida, com certa frequência, no discurso acadêmico. A título de ilustração, cabe um dos trechos de textos do corpus em que se encontram instanciações das duas microconstruções, com o alinhamento funcional supracitado.

Ex. 5: As bolhas, ao subirem, aumentam de tamanho por redução da pressão e coalescimento com outras bolhas, arrastando grande quantidade de material particulado na sua subida. São elas responsáveis pela grande taxa de circulação de sólidos no leito. A elevação continuada da vazão, nesta condição, provoca somente o aumento do número e tamanho das bolhas, sem elevar a pressão na base da grelha. Quando a velocidade do gás atinge a velocidade terminal das partículas (Ut) começa a haver [um arraste do material mais fino], diminuindo a altura do leito e a pressão na 63 sua base. No caso destas partículas arrastadas serem coletadas em um ciclone14, ou outro dispositivo semelhante, e serem retornadas ao leito, têm-se [um leito fluidizado circulante]. Quando não há [este retorno], têm-se [um leito de arraste]. [DM, 2004]

O fenômeno da variação linguística revela-se, grosso modo, em dois casos de relação semântica: em casos de representação linguística entre os quais se estabelece relação de sinonímia ou identidade (mesmo valor de verdade) e em casos de representação linguística entre os quais se percebe relação de comparabilidade funcional (parecença, alinhamento). Detecta-se, entre os constructos ${ }^{3}$ das microconstruções independentes aqui em foco,

3 Constructos são as ocorrências individuais observáveis, as instanciações de padrões construcionais (micro/meso/macro)construções. 
uma relação do segundo tipo, para a qual contribui o pensamento analógico, ou seja, o reconhecimento de similaridades formais ou funcionais entre duas ou mais (micro) construções.

Entende-se, assim como Saraiva (2013), que as instanciações da microconstrução com ter-se (cuja forma verbal, em muitas ocorrências do corpus, se manifesta nas formas de presente, tem-se/têm-se) resultam de um processo de mudança ${ }^{4}$ em razão do qual a forma verbal em questão se cristaliza com o clítico e se assemelha, em alguns contextos, a construções com se em estruturas de indeterminação do sujeito e, em outros, chega mesmo a corresponder a construções existenciais ou apresentacionais, como se observa em exemplos como:

Ex. 6: “Após essa classificação, Mattoso apresenta uma outra categoria, que seria a dos conectivos. Para ele conectivos seriam morfemas gramaticais usados para relacionar nomes, verbos e pronomes. À exemplo têm-se a palavra 'como' no corpus dado." [AG, 2014]

Ex. 7: "Sendo assim, sintetizando as variáveis que influenciam na Sociabilidade de acordo com lista apresentada no item 3.4, tem-se a seguinte relação: Presença de Pessoas, comportamentos antissociais e criminalidade; Paisagem Natural; Paisagem Construída; Limpeza; Volume de Veículos, Diversidade de uso do solo (presença de bares e Restaurantes), Áreas de Repouso e Convívio (parques, praças, largos etc). [DM, 2014]

Nos contextos em que as instanciações da microconstrução com ter-se assumem estatuto similar ao de instâncias de uma microconstrução com haver impessoal, aquelas revelam funcionamento discursivo-pragmático de impessoalidade (especialmente no discurso acadêmico) e têm estatuto de

\footnotetext{
${ }^{4}$ Em Saraiva (2013), esse processo foi abordado sob a ótica da gramaticalização de construções. E, agora, se supõe a viabilidade de um processo de "construcionalização gramatical" que gera, como resultado, um nó na rede de construç̃̃es gramaticais, pois o concescos no âmbito do enfoque construcio de Traugott; Trousdale (2013) e cogitamos a reconfiguração desse tratamento inicial à luz de una investigação diacrônica.
}

variante que ocorre em lugar de instâncias da microconstrução com essa funcionalidade ter $+S N$, já convencionalizada na fala (principalmente na fala estilisticamente menos monitorada).

Alguns estudos (cf. CALLOU; DUARTE, 2005 e CALLOU; AVELAR, 2007) chamam a atenção para o fato de que, na modalidade oral, na alternância entre os predicadores ter e haver, é alto o índice de uso do verbo ter em predicações impessoais (tal qual como aparece nos exemplos abaixo); entretanto, na modalidade escrita, há uma forte resistência ao uso dessa forma verbal com valor impessoal.

Ex. 8: “tem uma coisa interessante ... nos períodos de crise econômica a ... população fica mais exigente do ponto de vista moral ... e é absolutamente natural." [ERV, 2014]

Ex. 9: "Tem uma turma de bons e uma turma de péssimos." [AC, 2013]

Ex. 10: "Os americanos até ampliaram a vantagem. Mas tem uma novidade: uma parte razoável é de fora do 1ํo mundo." [AC, 2010]

Há, ainda, estudos (AVELAR, 2004, e CALLOU \& DUARTE, 2005) que destacam usos de ter acompanhado do pronome você com referência indefinida ou arbitrária que têm a funcionalidade de impessoalização no discurso. Com esta referência, o pronome pode até ser tratado como um possível expletivo. Também já se detectaram construções desse tipo, tais como a seguinte:

Ex.11: "Por ocasião das comemorações do centenário da independência do Brasil, você teve muitos hotéis inaugurados no Rio de Janeiro." [trecho de comentário oral sobre aspectos históricos da orla carioca, rádio MEC, 01/03/2013]

Também esses usos são rechaçados na modalidade escrita. Empregos de ter com valor impessoal que tendem a ser percebidos como naturais na escrita normalmente ocorrem na primeira pessoa do plural (acompa- 
nhados ou não de pronome nós), como os que vemos em estruturas tais como:

Ex. 12: "Já na classe dos verbos temos "engenhei" e eternizou-se." [AG, 2014]

Ex.13: "No exemplo (b), temos o adjunto "Com o tempo" antes do sujeito "os pais", uma construção que está posta para caracterizar a gradação de como a ação "descobrir" irá acontecer." [AG, 2014]

Ex. 14: “o que HOJE não se consegue é adaptar... não existe nenhuma estratégia... eh:... de manutenção da MÁXIMA da biodiversidade que nós temos... eh... nós estamos num terreno que...que....não tem [ ] conhecimento... eh:... infelizmente talvez não tenha solução...quer dizer não é só uma questão de conhecimento... talvez NÃO E-XIS-TA... realmente UMA SO-LUÇÃO... por exemplo às vezes as pessoas acham que não tem muita vida no ártico... ou que... que o ícone é o urso polar... terá dificuldade até de sobrevivência num... num futuro que não está muito distante do oceano ártico SEM gelo durante o fim do verão ou durante boa parte do verão... isso pode acontecer daqui a trinta quarenta cinquenta sessenta anos mas vai acontecer... porque não dá mais para parar a máquina de derretimento do gelo do ártico... mas tem... milhares e milhares de espécies... biológicas que vivem na interface do gelo... com o oceano... todas essas espécies vão desaparecer... e existe gelo no ártico há muitos e muitos milhões de anos..." [ERV, 2013둔

Na escrita acadêmica, também se resolvem restrições ao emprego de ter (tem ou teve, entre outras possibilidades, acompanhado ou não pelo pronome você com valor impessoal), recorrendo-se ao emprego de ter-se + $S N$, microconstrução que não é rechaçada na escrita, como revela o estudo de Saraiva (2013).

\footnotetext{
5 A partir da audição da entrevista no site do programa Roda Viva da TV Cultura <http://tvcultura. cmais com ar/rodavivas, transcreveu-se esse trecho da entrevista procurando-se seguir normas de transcrição mais comumente utilizadas em acervos de dados (como APERJ, NURC-RI).
}

A impessoalização discursiva é uma estratégia de polidez ou preservação da face (BROWN; LEVINSON, 1987) comum no discurso acadêmico: uma forma de impedir, atenuar ou reparar eventuais ameaças à face do locutor ou interlocutor na interação comunicativa, por meio da distância imposta ao conteúdo proposicional em relação àquele. Logo, nada mais natural que, no domínio discursivo acadêmico, haja lugar para a reconfiguração dos padrões construcionais envolvidos no fenômeno de variação entre haver e ter impessoais comum na fala, com o intuito de se reestabelecer, principalmente na escrita, a variação relacionada a tais formas verbais.

Com isso, supõe-se que o mecanismo de analogização tenha levado a usos que, especialmente no discurso acadêmico, se vêm convencionalizando nesse tipo de microconstrução, mediante a associação de propriedades de pareamentos de forma e função como: a construção com pronome se indeterminador de argumento, as construções existencial e apresentacional às quais se compatibiliza o verbo ter (com suspensão de argumento) e a construção de estado de posse psicológica com que ter também se compatibiliza. É possível que a microconstrução ter $S N$ se venha convencionalizando no discurso como mecanismo para perspectivar algum grau de polidez ou preservação da face, haja vista o fato de:

Constructions can also serve to deemphasize an argument by specifically shading an argument. The term shading is intended to invoke the idea of casting a participant in the shadows: the participant is present semantically, but is not "under the spotlight." One example of this type of construction is the passive construction, which shades or deprofiles the agent argument. (GOLDBERG, 2005)

6 "As construç̃̃es também podem servir para enfatizar um argumento, sombreando especificamente um argumento. 0 termo sombreamento destina-se a invocar a ideia de lançar um participante nas sombras: o participante está presente semanticamente, mas não está "sob destaque". Um exemplo desse tipo de o participante está presente semanticamente, mas não está "sob destaque". Um exem 
Daí advém o interesse em investigar em que medida ter-se $S N$ vem ganhando espaço como mecanismo de marcação de valor impessoal e, particularmente, na escrita acadêmica.

Diante do quadro aqui brevemente exposto, interessa examinar: (i) em que medida a microconstrução ter-se $+S N$ passa a competir com a microconstrução haver $+S N$ e se já há indícios de mudança em prol daquela, de convencionalização daquela; e (ii) quais são os condicionamentos da alternância dessas microconstruções de impessoalização. Pretende-se, em linhas gerais, descrever os fatores linguísticos e/ou extralinguísticos que interferem na tendência ao emprego de instâncias dessas microconstruções.

Tenciona-se, por fim, considerar subsídios dessa pesquisa sociofuncionalista em prol do debate sobre o lugar da variação linguística no modelo de rede de construções gramaticais, que se assume no âmbito da Linguística Funcional-Cognitiva e que tem, entre suas referências, Traugott; Trousdale (2013) e Goldberg (1995).

\section{Enfoque teórico-metodológico}

A descrição que se propõe aqui procura pautar-se na articulação de pressupostos da Teoria da Variação e Mudança (WEINREICH; LABOV; HERZOG, 1968, LABOV, 1994) sobre os problemas dos condicionamentos e da transição, de pressupostos do Funcionalismo (LAVANDERA, 1984, HOPPER, 1991, BYBEE, 2003) relativos principalmente aos parâmetros de comparabilidade funcional e frequência como fenômenos envolvidos no processo de mudança e de pressupostos sobre a rede de construções gramaticais e do estudo de variação e mudança num enfoque construcional (TRAUGOTT; TROUSDALE, 2013, HILPERT, 2014). Adota-se, por conseguinte, em certa medida um olhar sociofuncionalista (TAVARES, 2013) na análise dos dados (coletados em textos produzidos no domínio acadêmico-cien- tífico) e na interpretação dos resultados. Parte-se da ideia de que "the grammar provides several ways to encode a given category of events" 7 (PEREK, 2015, p. 145).

Quanto às construções impessoais estudadas especificamente, concebese, a partir da descrição em Saraiva (2013), que ter-se SN impessoal tem adquirido funcionalidade discursivo-pragmática diferente: a construção ter-se $S N$ é usada para que se possa tornar opaca a presença do autor/ enunciador na expressão de uma conclusão, de uma opinião, de uma avaliação, de um estado de coisas. Esse tipo de atitude compatibiliza-se com o que tipicamente se espera no domínio acadêmico, em que não se põe em evidência o pesquisador/cientista. As duas estratégias corresponderiam, então, neste domínio discursivo, à marcação destas atitudes: (a) levar a predicação a não se centrar no emissor, ou seja, a um grau [quase] nulo de subjetivização, mediante haver $S N$, ou (b) fazer a predicação estar um pouco mais centrada no emissor, mesmo que este se configure de maneira opaca, ou seja, a algum grau (baixo) de subjetivização, por meio de ter-se $S N$. Destaca-se que a microconstrução com haver, apesar de ser consideravelmente utilizada em sentenças "existenciais", aparece também de forma significativa como estratégia de impessoalização do discurso, haja vista exemplos como 3 (já citado): "Se por um lado há o propósito de parodiar os antigos tratados, por outro existe a denúncia da moral dupla de seu tempo." Nesse exemplo, o uso "há o propósito de parodiar (...)" pode relacionar-se tanto a "tem-se o propósito de parodiar" como a uma expressão com verbo simples semanticamente correspondente ao complexo haver $+S N$ : "objetiva-se parodiar, quer-se parodiar". Também se percebe a viabilidade dessa comparabilidade funcional no exemplo 5 ("Para a qualidade no setor de serviços a terceira abordagem é a mais adotada, pois, apesar de não haver

7 "A gramática propicia diversos caminhos para codificar uma dada categoria de eventos." 
na literatura uma convergência de opiniões."): "não haver uma convergência de opiniões", "não se ter uma convergência de opiniões" ou "opiniões não convergirem/não convergirem opiniões". E, ainda, se verifica em exemplo como: "há/tem-se a possibilidade de coletar dados/pode-se coletar dados".

Em outras palavras, em ambas microconstruções (com ter-se e com haver), revela-se a busca pela atenuação e/ou apagamento das marcas de primeira pessoa discursiva na expressão de uma opinião, avaliação ou conclusão, a fim de deixar o texto mais objetivo. Naturalmente, elas colaboram para isso diferentemente: enquanto a microconstrução com haver promove a anulação do enunciador; a microconstrução com ter-se torna opaca sua existência, e, ainda, pode colaborar para que a semântica final da predicação tenha um valor genérico. De todo modo, constituem microconstruções passíveis de comparabilidade funcional. E essa comparabilidade já está sendo confirmada pelos resultados dos primeiros testes de percepção que se vêm desenvolvendo, no âmbito da pesquisa experimental do Projeto PREDICAR, sobre o grau de proximidade entre os efeitos de sentido em dados oriundos dessas microconstruções ${ }^{8}$. Assim sendo, tais microconstruções passam a funcionar como alternativas de expressão linguística, embora estejam associadas a contextos condicionadores.

Entre conceitos basilares do enfoque construcional, está o de construção e o de níveis de esquematicidade construcional. Construções (desde afixos até cláusulas inteiras) são as unidades básicas da língua (GOLDBERG, 1995), pareamentos de forma (prosódica, fonético-fonológica, morfológica e

${ }^{8}$ Com base em metodologia experimental (FASOLD, 1987), está em curso, no âmbito do Projeto PREDICAR, um estudo sobre (i) atitudes quanto à relação entre o emprego de constructos das microconstruções aqui em análise e certas dimensões (modalidade expressiva, área do conhecimento, natureza semântica/genericidade da predicação, grau de formalidade, relação de poder ou distância entre os interlocutores, grau de correção linguística) e (ii) percepção quanto ao grau de equivalência funcional dessas construções com base no método semidireto, na técnica de escalas semânticas, na formulários (testes de atitudes). sintática) e sentido (função semântica, discursiva e pragmática). De acordo com Traugott; Trousdale (2013), para se compreenderem as diferenças e semelhanças entre os padrões construcionais, é preciso levar em conta a existência de quatro níveis (do mais geral e abstrato (primitivo, possivelmente, universal) até o mais específico e concreto): 1) Macroconstruções/ Esquemas construcionais são os pareamentos mais gerais/genéricos de uma rede construcional que abarcam estruturas complexas com slots (possibilidades diversas de preenchimento); 2) Mesoconstruções/ Subesquemas construcionais constituem os conjuntos de construções individuais com similaridades observáveis; 3) Microconstruções são as construções individuais (pareamentos, ainda abstratos, em potencial de se instanciarem em texto/discurso) e 4) Constructos são as ocorrências das microconstruções empiricamente atestadas nos discursos, ou seja, os usos concretos das construções individuais em textos e, consequentemente, o locus da inovação individual e, em esta sendo convencionalizada socialmente, da mudança construcional (ou transformação na forma ou alteração no sentido) e até construcionalização (pareamento de nova forma-novo sentido).

\subsection{Materiais em análise}

O corpus utilizado na análise sociofuncionalista por que se pauta a pesquisa foi obtido a partir de dados recolhidos em textos orais e escritos produzidos por falantes do meio acadêmico e submetido a uma análise estatística por variáveis independentes, utilizando-se, para tanto, o programa GoldVarb X (SANKOFF; TAGLIAMONTE; SMITH, 2005). Ademais, no intuito de checar elementos revelados nessa análise estatística dos dados recorreu-se, ainda, a registros obtidos com base em metodologia de pesquisa de percepções ou atitudes: procurou-se examinar como tais construções são percebidas pelos usuários da língua e, assim, fundamentar a análise das construções aqui focalizadas como passíveis de variação por conta de sua 
comparabilidade funcional em dados do comportamento observável e em percepções.

A amostra de construções com ter-se e haver conta com 328 dados ${ }^{9}$, distribuídos em dois períodos de tempo e coletados nestes gêneros do domínio acadêmico:

Quadro 1 - Gêneros considerados na constituição da amostra de usos de ter-se e haver

\begin{tabular}{|l|l|}
\hline $\mathbf{2 0 0 0 - 2 0 0 4}$ & $\mathbf{2 0 1 0 - 2 0 1 4}$ \\
\hline Artigos científicos & Artigos científicos \\
\hline Resumos de comunicações & Resumos de comunicações \\
\hline Dissertações de Mestrado & Dissertações de Mestrado \\
\hline $\begin{array}{l}\text { Transcrições de entrevistas do programa } \\
\text { Roda Viva (TV Cultura)* }\end{array}$ & $\begin{array}{l}\text { Transcrições de entrevistas do programa } \\
\text { Roda Viva (TV Cultura) }\end{array}$ \\
\hline 164 dados & 164 dados \\
\hline
\end{tabular}

* Neste caso, só se consideraram entrevistas realizadas com falantes que, em alguma medida, mantêm vínculo com instituições acadêmicas. Recorreu-se a transcrições disponibilizadas no site Memória Roda Viva: <http://www.rodaviva.fapesp.br/>. Em outros casos, procedeu-se à transcrição de dados identificados em programas ouvidos no portal do site http://tvcultura.cmais.com.br/rodaviva.

\subsection{Procedimentos de análise na construção impessoal \\ Vestado impessoal + SN}

Procedeu-se ao tratamento qualitativo e quantitativo de dados do comportamento observável em materiais do domínio discursivo acadêmico.

Ao final do levantamento de dados, teve-se o cuidado de examinar dado a dado no intuito de verificar se a permuta entre as formas verbais causaria alguma nuance de sentido muito diferente à sentença original, o que poderia inviabilizar o pressuposto de comparabilidade funcional entre as formas alternantes em estudo. Tal procedimento baseou-se na concepção de que

\footnotetext{
9 No período 2000-2004, só houve tempo de coletar 164 dados. No período de 2010-2014, houve tempo de reunir muitos dados. Tendo em vista o conjunto de dados obtido no primeiro recorte temporal, decidiu-se considerar apenas os 164 primeiros dados coletados no período 2010-2014.
}

o alinhamento funcional entre os constructos das microconstruções em análise resvala, num continuum de referencialidade, desde a opacificação do participante até a sua suspensão. Em nenhum dado considerado nessa amostra, a testagem da permuta entre as formas verbais causou alteração (substancial) do sentido da sentença original. Por isso, apesar de o corpus também conter casos em que se identificou um menor nível de equivalência semântica (por conta da possibilidade de cada variante contribuir para acentuar algum matiz de sentido), os dados foram submetidos à análise variacionista, pois não se verificou a impossibilidade de uso de ambas as formas em análise em qualquer contexto do corpus.

Trabalhou-se com a hipótese de que, ao entrar em relação de comparabilidade funcional com haver $S N$, ter-se $S N$ pode sujeitar-se a influências como:

Quadro 2 - Variáveis ${ }^{10}$ para o exame do fenômeno em estudo

\begin{tabular}{|l|l|}
\hline Natureza semântica do SN & Tempo \\
\hline Configuração sintática do SN & Modalidade expressiva \\
\hline Estrutura da predicação & Gênero textual \\
\hline Natureza semântica da predicação & Área do conhecimento \\
\hline Posição das variantes no período & \\
\hline
\end{tabular}

Estipularam-se, então, os grupos de fatores a investigar a partir dessas possíveis influências. A análise da amostra de dados fundamenta-se, basicamente, no olhar sociofuncionalista do problema dos condicionamentos linguísticos e extralinguísticos relacionados à variação entre essas construções verbais e do problema de transição, levando-se em conta os

${ }^{10}$ A definição dessas variáveis teve como ponto de partida os grupos de fatores considerados na pesquis de Mestrado de Saraiva (2013), que detectou a recorrência à microconstrução ter SN impessoal especialmente no discurso acadêmico. 
intervalos de tempo descritos em 2.2. Neste caso, o intuito é o de observar a mudança em tempo real de curta duração com base num estudo de tendências que se manifestem na comparação dos dois intervalos de tempo considerados.

Além dessas variáveis, procurou-se observar, como grupos de controle das instanciações das construções em estudo: a presença de elemento passível de atuar como atrator de pronome clítico em contextos estruturados por ter-se e o grau de equivalência semântica entre as construções estudadas.

\section{A variação de instâncias de uso de microconstruções com ter-se e haver impessoais no discurso acadêmico}

O tratamento estatístico dos dados revela que as construções impessoais/ existenciais no Português acadêmico escrito ou oral são produtivamente estruturadas com o verbo haver: em 328 contextos desse tipo de construção no corpus, apenas 45 ocorrências de construções com ter-se (14\%) foram registradas.

Gráfico 1 - Distribuição de formas verbais de impessoalização em amostra do discurso acadêmico

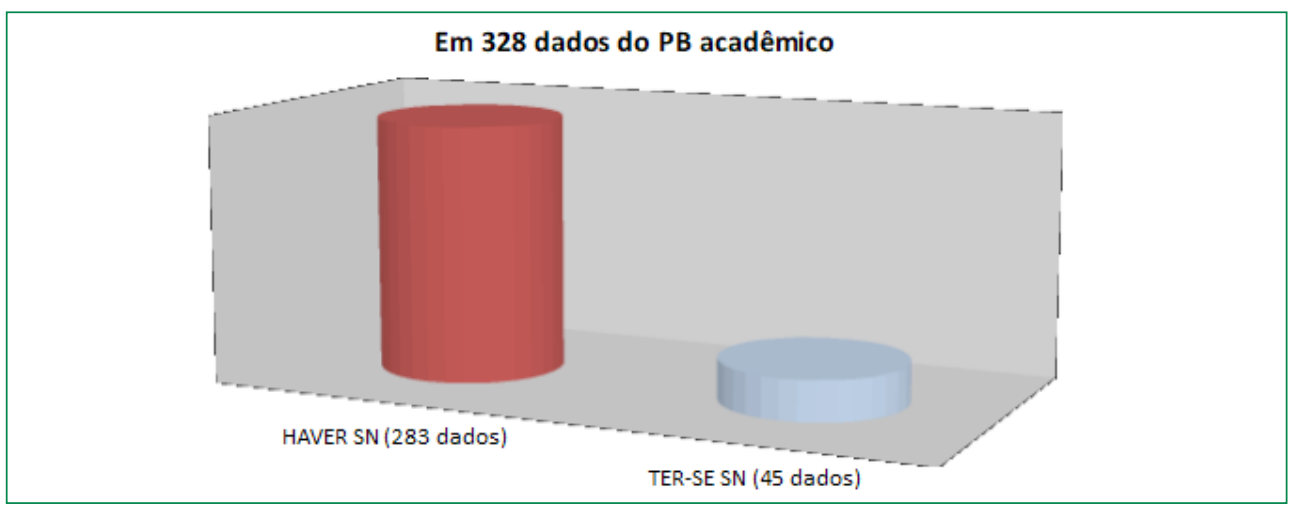

De acordo com Labov (2003), pode-se caracterizar a alternância das construções com ter-se e haver, na modalidade acadêmica, como uma regra variável ao se focalizarem os números absolutos, já que o percentual de uso da estrutura com verbo haver se situa entre 5 e 95\%: 86,30\% (283 ocorrências). Os resultados confirmam a hipótese de que instanciações da microconstrução com ter-se $(13,70 \%)$ aparecem como alternativa de impessoalização que vem ganhando espaço nos últimos tempos:

Tabela 1 - Percentuais e pesos relativos das construções com ter-se no domínio acadêmico pela variável tempo real de curta duração ${ }^{11}$

\begin{tabular}{ccc}
\hline Tempo Real & $\begin{array}{c}\text { Ocorrências/Total de Contextos } \\
\text { (\%) }\end{array}$ & Peso Relativo \\
\hline $2000-2004$ & $17 / 164(10,4)$ & 0.138 \\
$2010-2014$ & $28 / 164(17,1)$ & 0.816 \\
\hline
\end{tabular}

E instâncias de uso da microconstrução ter-se $S N$ vêm ganhando espaço especialmente na modalidade escrita do domínio discursivo acadêmico, justamente onde raramente é encontrado o emprego da microconstrução com ter impessoal, que também entra em competição com instâncias de uso da microconstrução com haver em outros contextos. No levantamento de dados feito nas entrevistas do programa Roda Viva, notou-se que há mais ocorrências de ter $S N$ do que ter-se $S N$ (cf. Tabela 3), embora, também nessa fonte, a construção impessoal com haver venha mostrando-se, ainda, mais recorrente.

Dentre as variáveis independentes examinadas, destacaram-se sistematicamente, na análise estatística, estes condicionamentos: tempo

${ }^{11}$ Valor de aplicação nas rodadas do programa Goldvarb X: construções com ter-se. Significância do níve selecionado: 0.038 
(cf. Tabela 1) e área do conhecimento. Também mostraram alguma relevância: o gênero textual; a natureza semântica do SN da construção; a posição da construção no período; presença, no período, de vocábulo passível de atuar como atrator de clítico SE (presente numa das variantes em análise); a natureza da sentença; o grau de equivalência semântica entre as formas ter-se e haver.

$\mathrm{Na}$ análise dos fatores de ordem social considerados, detectou-se uma propensão ao emprego de instâncias da microconstrução com ter-se em textos das áreas de Engenharia e Arquitetura: 55,8\% de expressões com ter-se.

Tabela 2 - Percentuais e pesos relativos das construções com ter-se no domínio acadêmico pela variável área do conhecimento

\begin{tabular}{lcc}
\hline Área do Conhecimento & $\begin{array}{c}\text { Ocorrências/Total de Contextos } \\
(\%)\end{array}$ & $\begin{array}{c}\text { Peso Relativo } \\
\text { Engenharia e Arquitetura }\end{array}$ \\
Letras, Educação, Comunicação Social & $\mathbf{2 4 / 4 3 ( 5 5 , 8 )}$ & $\mathbf{0 . 7 9 0}$ \\
Saúde e Esporte & $1 / 44(2,3)$ & 0.308 \\
História, Antropologia e Arqueologia & $3 / 24(12,5)$ & 0.190 \\
Filosofia, Sociologia, Política, Economia & $6 / 53(11,3)$ & 0.591 \\
Outra & $7 / 69(10,1)$ & 0.563 \\
\hline
\end{tabular}

Um uso mais expressivo dessa variante na área de Engenharia também já tinha sido observado por Saraiva (2013). Dessa tabela, depreende-se, ainda, que - nos textos das áreas de Saúde e Esporte e Letras, Educação e Comunicação Social - ainda é baixa a frequência de uso de construções com ter-se. Nas demais áreas, os pesos relativos estão bem próximos ao ponto neutro (0.500), resultado que sinaliza ambiente propício a ambas variantes, embora, em termos de realização, os índices percentuais mostrem poucos casos no corpus de construções com ter-se.
É interessante observar, quanto aos dados das áreas de Engenharia e Arquitetura, que muitas predicações nas quais se detectaram construções com ter-se revelam a perspectiva do enunciador de focalizar ou apresentar fórmulas, resultados, consequências, especificações técnicas, como ocorre nos exemplos abaixo:

Ex.15: "Tem-se então $\{\mathrm{h} 2, \gamma$ o2 $\}$ e assim por diante até observar-se uma diminuição de peso da amostra compacta. Geralmente são procedidos 5 ensaios em 5 umidades diferentes." [RC, 2004]

Ex.16: "No aspecto econômico tem-se: menor importação de fertilizantes químicos, considerável redução da necessidade de fertilizante artificial; produção de alimentos e conservação do solo com lodos de tratamento biológico." [RC, 2004]

Ex.17: "Se forem avaliadas também como resíduos a biomassa da folhagem da planta, a palha e as pontas da cana, tem-se o coeficiente de resíduo entre 0,70 e 0,90 e o coeficiente de disponibilidade variando de $35 \%$ ao máximo de $100 \%$ (quando apenas o bagaço estiver realmente disponível e quando toda a biomassa encontra condições técnico-econômicas de aproveitamento, respectivamente)." [DM, 2004]

Os resultados obtidos na análise da variável gênero textual permitem mostrar, com mais nitidez, que, em artigos científicos da área de Letras e na oralidade ${ }^{12}$, ainda é muito pequena a tendência ao emprego da construção ter-se $S N$. Ao que tudo indica, essa construção tende a aparecer mais significativamente em dissertações de Mestrado (0.822 de peso relativo nesse contexto).

${ }^{12}$ Vale lembrar que, nas entrevistas do programa Roda Viva, há, ainda, instanciação da microconstrução com ter impessoal (sem o clítico SE). 
Tabela 3 - Percentuais e pesos relativos das construções com ter-se no domínio acadêmico pela variável gênero textual

\begin{tabular}{lcc}
\hline Gênero Textual & $\begin{array}{c}\text { Ocorrências/Total de Contextos } \\
(\mathbf{\%})\end{array}$ & $\begin{array}{c}\text { Peso Relativo } \\
\text { Artigos Científicos (áreas diversas) }\end{array}$ \\
Artigos Científicos (área de Letras) & $\mathbf{1 3 / 8 4}(\mathbf{1 5 , 5 )}$ & $\mathbf{0 . 6 2 1}$ \\
Resumos (áreas diversas) & $1 / 50(2,0)$ & 0.155 \\
Dissertações de Mestrado (áreas diversas) & $\mathbf{1 4 / 9 1}(\mathbf{1 5 , 4 )}$ & $\mathbf{0 . 6 1 9}$ \\
Entrevistas Roda Viva (TV Cultura) & $\mathbf{1 5 / 4 4}(\mathbf{3 4 , 1 )}$ & $\mathbf{0 . 8 2 2}$ \\
\hline
\end{tabular}

Talvez isso se explique pelo fato de haver necessidade de se recorrer ao uso da construção ter-se $S N$ em textos mais extensos como mais uma estratégia que leva à versatilidade sintática, para que o número de outras marcas gramaticais de impessoalização seja reduzido, e, assim, mostre-se, além de domínio de um vasto repertório de formas da língua portuguesa, equilíbrio no emprego delas.

Também não se pode ignorar a influência de outras construções por paralelismo discursivo, já que as dissertações são gêneros textuais em que as construções com SE são produtivas. Colaboram, para esse fenômeno, o fato de as construções ter-se $S N$ partilharem semelhanças com construções com se ou em estruturas de passiva sintética ou em estruturas de indeterminação do sujeito, bem como o fato de, na modalidade escrita, haver uma forte resistência ao uso de ter com valor impessoal. Assim sendo, ter-se SN passa a competir com a forma verbal haver $S N$ nesse gênero acadêmico.

Uma variável que não pôde ser avaliada pelo aplicativo ivarb do programa GoldVarb X e que revelou comportamento importante é a natureza semântica do SN das construções impessoais em análise. Todas as 24 construções com SN animado (como as dos exemplos 19 e 20) são constituídas por haver:
Tabela 4 - Percentuais e pesos relativos das construções com ter-se no domínio acadêmico pela variável natureza semântica

\begin{tabular}{lcc}
\hline Animacidade & $\begin{array}{c}\text { Ocorrências/Total de contextos } \\
\text { (\%) }\end{array}$ & $\begin{array}{c}\text { Peso Relativo } \\
\text { Inanimado (evento) }\end{array}$ \\
Inanimado (abstrato) & $\mathbf{2 7 / 1 6 6 ( 1 6 , 3 )}$ & $\mathbf{0 . 5 3 1}$ \\
Inanimado (concreto) $^{*}$ & $\mathbf{1 0 / 7 0}(14,3)$ & $\mathbf{0 . 4 9 3}$ \\
Animado humano (ou não) & $\mathbf{5 / 3 6 ( 1 3 , 9 )}$ & $\mathbf{0 . 4 8 4}$ \\
\hline
\end{tabular}

* Cf. exemplo 5: têm-se [um leito fluidizado circulante].

Ao que parece, as construções com SN inanimado são os contextos que instanciam a variação de ter-se e haver (os pesos relativos, nesse caso, ficam próximos ao ponto neutro, 0.500), conforme ilustram os enunciados abaixo:

Ex. 18: "No quadro 4-A foi possível perceber que há uma discussão sobre a questão da escola ( 3 trabalhos) enfatizando a relação com redes sociais, as questões de gênero e o debate com a questão da saúde." [AC, 2014] SN Inanimado evento (cf., também, exs. 1 e 23)

Ex. 19: "Como a base de dados foi composta por 48 textos, quatro para cada uma das 12 classes de autores, teve-se um total de 48 classificações e gerouse uma matriz de confusão." [RC, 2010] - SN Inanimado abstrato

Ex. 20: "No Brasil, de acordo com as estimativas do IBGE realizadas no censo 2000, há cerca de 300 mil portadores de Síndrome de Down." [RC, 2010] - SN humano

Ex. 21: "Mesmo nos Estados Unidos, contudo, há também arqueólogos com outras formações, como é o caso dos arqueólogos clássicos, que estudam as civilizações grega e romana, cujo estudo liga-se às letras clássicas, à história e à história da arte, em medidas variadas, segundo a tradição de cada instituição. Há, ainda, os arqueólogos da orientalística. [AC, 2000] - SN humano 
Ex. 22: “De como isso se efetiva há inúmeros exemplos na própria obra de Luciano (como seus diálogos de mortos), embora nenhum tão consequente com o estatuto tirânico do narrador quanto Narrativas verdadeiras [Alethôn diegemáton]." [AC, 2010] - SN Inanimado abstrato (cf., também, ex. 26)

Verificou-se, ainda, que a construção com ter-se normalmente não ocupa a posição inicial do período.

Tabela 5 - Percentuais e pesos relativos das construções com ter-se no domínio acadêmico pela variável posição no período

\begin{tabular}{|lcc}
\hline Posição no Período & $\begin{array}{c}\text { Ocorrências/Total de contextos } \\
(\%)\end{array}$ & $\begin{array}{c}\text { Peso Relativo } \\
\text { Inicial (início absoluto) }\end{array}$ \\
\hline Não - inicial & $2 / 75(2,7)$ & 0.175 \\
\hline
\end{tabular}

Quando essa construção ocorre, geralmente há alguma expressão circunstancial ou caracterizadora no início. A título de ilustração, observemse exemplos como o 16 e este:

Ex. 23: “Com o crescente aumento populacional, o consumo de água no planeta também tem aumentado e, unindo-se a isto, tem-se grande produção de esgotos que são lançados inadequadamente em corpos d'água, causando eutrofização; portanto, para evitar essa agressão ao meio aquático, faz-se necessário tratar convenientemente os esgotos domésticos removendo principalmente matéria orgânica, nitrogênio e fósforo." [RC, 2004]

Ainda com interesse em investigar a estrutura em que tal construção tende a ocorrer, procurou-se observar a presença, no período, de vocábulo passível de atuar como atrator de clítico SE (presente apenas numa das variantes em análise).

Procedeu-se desse modo com a intenção de examinar se (i) o comportamento gramatical e cristalizado da construção impessoal ter-se (que, em muitos dados, tem a forma tem-se/têm-se, teve-se, tinha-se) se mantém mesmo na presença de vocábulos que supostamente servem de atratores do pronome oblíquo para a posição proclítica ou se (ii), em razão de tal contexto, a tendência ao emprego da forma haver se acentua, justamente para se evitar alterar a estruturação dessa forma, que se revela fossilizada. Obteve-se, então, um resultado que colabora para a hipótese de fixação da construção:

Tabela 6 - Percentuais e pesos relativos das construções com ter-se no domínio acadêmico pelo grupo de fatores contexto com ou sem elemento proclisador

\begin{tabular}{lcc}
\hline Contexto & $\begin{array}{c}\text { Ocorrências/Total de Contextos } \\
(\%)\end{array}$ & $\begin{array}{c}\text { Peso Relativo } \\
\text { SEM elemento proclisador }\end{array}$ \\
COM elemento proclisador & $\mathbf{3 0 / 1 2 2}(\mathbf{2 4 , 6 )}$ & $\mathbf{0 . 7 0 9}$ \\
\hline
\end{tabular}

Em meio à tendência geral ao emprego de haver em todos os contextos, com ou sem atrator, verifica-se que o índice de uso de haver é ainda mais significativo quando este está imediatamente após um proclisador, principalmente quando se segue a não:

Ex. 24: Os veículos de comunicação eram em número muito menor, não havia Internet, redes sociais, telefones celulares com câmeras e tantos outros meios de difundir informação. [AC, 2013]

Ex. 25: "O resultado desta pesquisa é normalmente apresentado em gráficos, onde em abcissa tem-se as unidades e em ordenadas o peso específico aparente seco." [RC, 2004]

Os resultados sugerem que a construção ter-se $S N$ é acionada pelo falante como uma construção cristalizada, que se materializa exatamente dessa forma no momento de sua utilização. Assim, em contextos propícios ao uso da próclise (ordem não marcada do PB), no texto acadêmico, tende- 
se a evitar ter-se ou empregar a construção com ênclise mesmo (cf. exemplo 25). Cabe dizer que: (i) raríssimas são as ocorrências de uso proclítico de se a ter no corpus; e (ii) que houve uma ocorrência de mesóclise (cf. exemplo 26), forma que, segundo estudos variacionistas sobre a ordem dos clíticos, tende a ser evitada.

Ex. 26: "A partir daí, pretende-se uma intervenção, a que se quer chegar não apenas a construção do conhecimento teórico, mas, também, contribuir com tais aldeias na estruturação da formação de seus docentes indígenas. Assim, ter-se-á, como critério básico da pesquisa que vem sendo desenvolvida, o 'princípio da participação': ele está na base do processo, nesta abordagem qualitativa de se fazer pesquisa; além disso, entrecruzando-se com uma questão contextual mais ampla, vem ao encontro do princípio constitucional da gestão democrática da educação, na medida em que a inclusão digital na educação indígena entra em interlocução com as decisões e opções específicas, valores, costumes, expectativas e interesses daquele espaço social e de educação." [RC, 2010]

Ter, ao se cristalizar com o clítico se, passa a corresponder a valor impessoal (existencial ou apresentacional). A construção passa a ser acionada de forma "automática" pelos usuários da língua com uma nova função discursiva que fica evidente nos textos analisados: a manutenção da neutralidade na expressão de estados de coisas ou a marcação de menor grau de envolvimento do autor do texto com a expressão de opiniões e posicionamentos.

Por fim, vale destacar que, em algumas construções, ter-se e haver parecem atuar como verbos suportes, ou seja, como operadores de verbalização de elementos não-verbais, podendo constituir com estes unidades/locuções de predicação cuja significação é principalmente definida pelo componente nominal. Por exemplo, vejam-se casos como tem-se a finalidade, por tenciona-se/objetiva-se, ou não há otimização, por não se otimiza, a seguir:
Ex. 27: "Quanto à transmissão de potência tem-se a finalidade de desenvolver novos sistemas redutores de velocidade, com o objetivo de aumentar o torque e o rendimento de uma fonte motriz seja elétrica ou mecânica." [RC, 2004]

Ex. 28: "concluiu-se que (...) c) não há otimização no uso do espaço físico disponível cujo critério de distribuição dos horários baseia-se na grade curricular e formação de equipes de treinamento implicando numa baixa relação custo benefício..." [RC, 2004]

Analisando-se os 88 contextos em que essa leitura é viável, verificou-se que, em apenas 11, ocorre ter-se.

Os resultados obtidos nessa pesquisa confirmam a hipótese de equivalência funcional de instâncias de uso da microconstrução ter-se $+S N$ com instâncias de uso da microconstrução impessoal haver $+S N$, bem como mostram motivações relativas ao emprego de expressões desses padrões gramaticais. Indicam que, com o passar do tempo, vem aumentando a frequência de recorrência à microconstrução ter-se $S N$ impessoal e que isso ocorre principalmente em textos acadêmicos das áreas de Engenharia e Arquitetura e/ou em dissertações de Mestrado. Colaboram, em última instância, para mapear, sociolinguisticamente, uma construção a que brasileiros recorrem cada vez com mais frequência no discurso acadêmico.

\section{Observação final: contribuição dos resultados da pesquisa sociofuncionalista à polêmica sobre o espaço da variação no modelo teórico de rede de construções gramaticais}

No modelo construcional, geralmente não se volta a atenção ao fenômeno de variação, haja vista o princípio de não-sinonímia (GOLDBERG, 1995, p.67): "If two constructions are syntatically distintic, they must be semantically or pragmatically distinct". 
O estudo aqui descrito evidencia, com base em dados do uso, a recorrência a dois tipos de expressões linguísticas a serviço da impessoalização discursiva no texto acadêmico. E um modelo linguístico voltado para o pareamento forma-significado/função convencionalizado em comunidade linguística, como é o modelo construcional, não pode deixar de lado a possibilidade de se lidar também com o fenômeno de variação na descrição da língua ${ }^{13}$, tanto no que diz respeito à competição quanto à convivência de variantes, que constituem construtos ligados a um ou mais padrões construcionais, a uma ou mais microconstruções gramaticais. Afinal, de acordo com Joan Bybee (TORRENT, 2012, p. 2),

The variation found in experience is represented at the deepest levels of representation and not treated as something that is tacked on the end of the grammar. Because variation is inherent to the grammar, gradual change is to be expected. ${ }^{14}$

Defende-se que a pesquisa sobre o conhecimento de uma lingua que abrigue a articulação variação-mudança como objetos teórico e observacional, na linha do que ocorreu nos estudos sociofuncionalistas voltados para a questão da mudança por gramaticalização (numa interação entre sincronia e diacronia), pode gerar generalizações sobre microconstruções e construções em rede a partir de constructos (dados do uso) relativas ao que há de "regular"/estável no sistema, ao que há de instável/variável (convivência, coexistência de variantes, variação estável; competição, mudança em

${ }^{13}$ Esta, em geral, se baseia apenas na observação da mudança (quer por alteração ou no polo da forma ou no polo do significado/função do padrão construcional - mudança construcional quer por construcionalizaça o, processo que resulta de alterações em ambos os polos da consquer por construcionalização, processo que resulta de alterações em ambos os polos da construção)

ñóção encontrada na experiência é representada nos níveis mais profundos de representação e algo que se soma no final da gramática. Como a variação é inerente à gramática, espera-se uma mudança gradual." progresso) e, também, ao que há de diferente ou ao que mudou (num estudo diacrônico em tempo real ou em tempo aparente detectado por estatísticas de frequências de uso via controle de gerações, níveis de escolaridade, até simplesmente de tradições linguísticas/discursivas num dado recorte do tempo). Nesse caso, aos pesquisadores interessados em focalizar mudança construcional ou construcionalização, o que daria o tom na admissão efetiva do estudo da variação seria, de fato, a mudança e, então, formas ou sentidos em competição formariam o objeto observacional. Não obstante, se o objetivo é alcançar as generalizações sobre conhecimento gramatical e lexical de uma língua, qualquer fenômeno (estabilidade, variação ou mudança) poderá constituir o objeto observacional se realmente se desejar descrever (num modelo multifatorial) todas as regiões do conhecimento de uma língua.

O quadro teórico construcional (a Linguística Funcional-Cognitiva que se alinha à Gramática das Construções), que enfatiza a relação entre uso e sistema linguístico subjacente à linguagem em uso, pode modelar o fenômeno da variação e propiciar referencial teórico-explicativo para o tratamento da interrelação de fatores (inclusive, estatísticos) que o afetam. Para tanto, talvez seja o caso de considerar o constructo teórico "allostructions". "Allostructions are (truth-)semantically equivalent but formally distinct manifestations of a more abstractly represented construction" 15 (CAPPELLE, 2009, p. 15). De acordo com PEREK (2015, p. 153), espraiando um pouco mais a analogia do termo allostructions com os termos alofones e alomorfes, Bert Cappelle sugere chamar a generalização herdada por allostructions como "constructeme".

15 “Allostructions são manifestações semanticamente equivalentes, mas formalmente distintas, de uma construção mais abstratamente representada" 
Importantly, this kind of representation aptly captures both aspects of an alternation. The constructeme and the inheritance links to each allostruction capture the fact that the constructions are similar and indicate at which level, and the allostructions themselves may include further syntactic and semantic/ pragmatic details as to how they differ from one another $(. . .)^{16}$. (PEREK, 2015, p. 153)

Supõe-se que as microconstruções ter $S N$, ter-se $S N$ e haver $S N$ possam funcionar efetivamente como allostructions de um padrão construcional, de nível mais abstrato na rede, com verbo de conteúdo existencial ou apresentacional e a serviço da impessoalização discusivo-pragmática.

\section{Referências}

AVELAR, Juanito. Dinâmicas morfossintáticas com "ter", "ser" e "estar" em português brasileiro. Dissertação (Mestrado) - Universidade de Campinas, Campinas, 2004.

BROWN, Penelope; LEVINSON, Stephen C. Politeness: some universals in language usage. Cambridge: Cambridge University Press, 1987.

BYBEE, Joan. Mechanisms of change in grammaticization: the role of frequency. In: BRIAN; RICHARD (Ed.). A handbook of historical linguistics. New York: Basil Blackwell, 2003.

CALLOU, Dinah Maria Isensee; AVELAR, Juanito. Gramática e variação no Português brasileiro: considerações sobre ter haver e de em. In: LOBO, M.; COUTINHO, M. A. (Org.). Textos Seleccionados - XXII Encontro da Associação Portuguesa de Linguística. Lisboa: Colibri, 2007.

CALLOU, Dinah Maria Isensee; DUARTE, M. Eugenia Lammoglia. A fixação do verbo ter em contextos existenciais. In: ENCONTRO DA ASSOCIAÇÃO PORTUGUESA DE LINGUÍSTICA, 20., 2005, Lisboa. Actas... Lisboa: APL, 2005.

CAPPELLE, Bert. Can we factor out free choice? In: DUFTER, A.; FLEISCHER, J.; SEILER, G. Describing and Modeling Variation in Grammar. Berlin/New York: Mouton de Gruyter, 2009, p. 183-199.

\footnotetext{
16 "Importante, esse tipo de representação apropriadamente capta ambos os aspectos de uma alternância. A construção e os links de herança para cada alocação capturam o fato de que as construções são semelhantes e indicam em qual nível, e as próprias allostructions também podem incluir detalhes sintáticos e semânticos/pragmáticos adicionais sobre como eles se diferenciam um do outro."
}

FASOLD, Ralph W. The Sociolinguístics of society. Oxford: Wiley-Blackwell, 1984 GOLDBERG, Adele. Constructions: A Construction Grammar Approach to Argument Structure. Chicago: The University of Chicago Press, 1995.

Argument realization: the role of constructions, lexical semantics and discourse factors. In: OOSTMAN, Jan-Ola; FRIED, Mirjam (Ed.). Construction Grammar(s): Cognitive and Cross-language dimensions. Philadelphia: John Benjamins, 2005.

HILPERT, Martin. Construction Grammar and its Aplication to English. Edinburgh: Edinburgh University Press, 2014

HOPPER, P. J. On some principles of grammaticalization. In: TRAUGOTT, E. C.; HEINE, B. (Ed.). Approaches to grammaticalization. v. I. Philadelphia: John Benjamins Company, 1991. <https://doi.org/10.1075/tsl.19.1.04hop>

LABOV, William. Some Sociolinguistic Principles. In.: PAULSTON, C. B.; TUCKER, G. R. (Ed.). Sociolinguistic: The Essential Readings. Oxford: Wiley-Blackwell, 2003.

Principles of Linguistic Change. Internal Factors. v. 1. Oxford: Blackwell, 1994

LAVANDERA, Beatriz. Variación y significado. Buenos Aires: Hachette, 1984.

PEREK, Florent. Argument structure in usage-based construction grammar. Experimental and corpus-based perspectives. Amsterdam: John Benjamins, 2015.

SANKOFF, David; TAGLIAMONTE, Sali A.; SMITH, Eric. GoldVarb X: Variable Rule Application for Macintosh and Windows. Toronto: University of Toronto, 2015.

SARAIVA, Eneile Santos. A construção TEM-SE no Português Brasileiro escrito: uma análise sociofuncionalista. 2013. 180 fl. Dissertação (Mestrado em Língua Portuguesa) - Faculdade de Letras, Universidade Federal do Rio de Janeiro, 2013.

TAVARES, M. Alice. Sociofuncionalismo: um duplo olhar sobre a variação e a mudança linguística. Interdisciplinar, ABRALIN, Itabaiana/SE, ano VI, v. 17, n. esp., p. 27-47, 2013

TRAUGOTT, Elizabeth C.; TROUSDALE, Graeme. Constructionalization and Construction changes. Great Britain: Oxford University Press, 2013.

WEINREICH, Uriel; LABOV, William; HERZOG, Marvin. I. Empirical foundations for a theory of language change, In: LEHMANN, W. P.; MALKIEL, Y. (Ed.). Directions for historical linguistics: A symposium. Austin-London, University of Texas Press, 1968. p. 97-195.

Artigo recebido em: 28/10/2016.

Artigo aceito em: 02/05/2017. 